\title{
The Feasibility of Discontinuing Lamivudine in Lamivudine-Resistant Chronic Hepatitis B Patients on Lamivudine and Adefovir Combination Therapy
}

\author{
Seong Min Chung Young-Sang Byoun Hee-Sup Kim Eun Sun Jang \\ Jin-Wook Kim Sook-Hyang Jeong
}

Department of Internal Medicine, Seoul National University College of Medicine, Seoul National University Bundang Hospital, Seongnam-si, Gyeonggi-do, Korea

\section{Key Words}

Hepatitis B virus · Lamivudine resistance · Adefovir .

Combination therapy

\section{Abstract}

Objectives: This study investigated the antiviral efficacy of adefovir (ADV) rescue therapy and the feasibility of lamivudine (LAM) discontinuation in LAM-resistant chronic hepatitis $B(C H-B)$ patients who had attained a virological response (VR) with LAM + ADV combination therapy. Methods: The VR and virological breakthrough (VBT) were analyzed in 106 consecutively enrolled LAM-resistant $\mathrm{CH}$-B patients who received $A D V$ rescue therapy during a mean follow-up period of 55.2 months. Seventy-four patients achieved VR, and were divided into the LAM-discontinuation group $(n=39)$ and the LAM-continuation group $(n=35)$. The VR and VBT between the 2 groups were compared. Results: For all 106 LAM-resistant $\mathrm{CH}-\mathrm{B}$ patients, the overall cumulative probabilities of VR at 1, 2, 3 and 5 years of ADV rescue therapy were 40.6, 55.7, 64.6 and $81.3 \%$, respectively. The cumulative probabilities of VBT at $1,2,3$ and 5 years were $0,2.9,8.8$ and $13.9 \%$, respectively. Whether they discontinued or continued LAM after achieving VR on LAM + ADV therapy, VR and VBT were not significantly different during a mean follow-up period of 40.4 months. Conclusions: There was a good long-term VR with $A D V$ rescue therapy for LAM-resistant $\mathrm{CH}-\mathrm{B}$ patients. Moreover, discontinuing LAM was found to be feasible for patients who attained VR during ADV + LAM therapy.

(c) 2014 S. Karger AG, Basel

\section{Introduction}

A persistently high level of serum hepatitis B virus (HBV) DNA is associated with an increased risk of cirrhosis, hepatocellular carcinoma and liver-related mortality [1-4]. As a major therapeutic tool for chronic hepatitis B (CH-B), nucleos(t)ide analogs suppress HBV replication and lead to a virological response (VR), defined as an undetectable level of serum HBV DNA, which improves long-term prognosis [5-8]. However, nucleos(t)

Seong Min Chung and Young-Sang Byoun contributed equally to this study.

\section{KARGER}

E-Mail karger@karger.com

www.karger.com/int
(C) 2014 S. Karger AG, Basel

$0300-5526 / 14 / 0576-0337 \$ 39.50 / 0$
Sook-Hyang Jeong, MD

Department of Internal Medicine, Seoul National University Bundang Hospital 82 Gumi-ro, 173 Beon-gil

Bundang-gu, Seongnam-si, Gyeonggi-do 463-707 (Korea)

E-Mail jsh@snubh.org 
ide analogs do not eradicate $\mathrm{HBV}$, and therefore longterm therapy is required, which can result in the emergence of drug resistance and high costs for drug administration [9].

Adefovir dipivoxil (ADV) is effective against both wild-type and lamivudine (LAM)-resistant HBV in compensated and decompensated patients [5, 6, 10-14]. For LAM-resistant patients, adding $\mathrm{ADV}$ on to previous LAM therapy (i.e. LAM + ADV combination therapy) showed significantly less ADV resistance than ADV single therapy (LAM to ADV switch therapy) [15-20]. However, it has not yet been studied if once a VR is attained with LAM + ADV combination therapy, administration of LAM should be combined indefinitely or could actually be discontinued [21-24]. Moreover, LAM and ADV are no longer first-line drugs for $\mathrm{CH}-\mathrm{B}$ patients in many countries since the introduction of entecavir (ETV) and tenofovir (TDF), both of which show higher antiviral potency and a higher resistance barrier than LAM or ADV.

In South Korea, reimbursement of the cost of LAM for LAM-resistant patients on the combination therapy was not permitted by National Health Insurance until a few years ago. So, according to their economic conditions, these patients had only the option of self-paid LAM and insurance-covered ADV for the LAM + ADV combination therapy or a discontinuation of LAM with insurancepaid ADV monotherapy $[23,25]$. Therefore, after achieving VR, many were willing to discontinue the self-paid LAM. Although the system of partial reimbursement was recently changed to include full coverage of the combination therapy, this previous restriction in health insurance presented a unique opportunity to compare the antiviral efficacy of a LAM-discontinuation group, i.e. patients on ADV single-maintenance therapy and a LAM-continuation group, i.e. patients on an indefinite combination of LAM + ADV after attaining VR.

The aims of this study were to clarify the long-term antiviral efficacy of ADV rescue therapy for LAM-resistant $\mathrm{CH}-\mathrm{B}$ and to investigate the feasibility of discontinuing LAM after achieving VR in the LAM-resistant $\mathrm{CH}-\mathrm{B}$ patients who were treated with the LAM + ADV combination therapy until a VR was achieved.

\section{Materials and Methods}

Patients

A total of 363 LAM-resistant CH-B patients were treated with ADV from June 2004 to December 2009 at the Seoul National University Bundang Hospital and then followed up until June 2013. After excluding patients with decompensated cirrhosis or hepato- cellular carcinoma at the initiation of ADV therapy, patients whose therapy was of short duration ( $<12$ months) and cases of poor compliance, 209 patients received ADV therapy for $>12$ months, with a compliance rate of $>80 \%$ by the pill-count method which was checked at every visit to the outpatient clinic. Cases where there was poor compliance after 12 months of ADV therapy $(\mathrm{n}=$ 11), readministration of LAM after an interval from the initiation of ADV therapy $(n=16)$, incomplete baseline data due to ADV administration having been started in another hospital $(n=32)$ and therapy consisting of ADV single-therapy only $(n=44)$ were excluded at this point.

The final subjects of this study were therefore 106 patients who received $\mathrm{ADV}+\mathrm{LAM}$ combination therapy after a resistance to LAM had emerged and the biochemical aggravation indicated by alanine aminotransferase (ALT) levels were $>2$ times the upper limit of normal. VR was achieved in 74 patients, who were divided into the LAM-discontinuation group $(\mathrm{n}=39)$ and the LAM-continuation group $(\mathrm{n}=35)$. The baseline characteristics, VR and virological breakthrough (VBT) of these 2 groups were compared. This study was approved by the institutional review board of this hospital, and informed consent was waived because of the retrospective analysis of medical records.

\section{Methods}

The clinical data were retrieved retrospectively from electronic medical records and entered into a computerized database. They included serum HBV DNA level, HBeAg status and biochemical liver function tests. Usual practice was for each patient to be followed up within 3 months of antiviral therapy and at intervals of 1-4 months thereafter. Serum HBV DNA level was quantified using signal amplification by the 7300 real-time PCR system (Applied Biosystems, Foster City, Calif., USA) and the detection limit was $60 \mathrm{IU} / \mathrm{ml}$ of serum in this hospital. Serum $\mathrm{HBeAg}$ and $\mathrm{HBeAb}$ were examined by ELISA (Abbott Laboratories, Chicago, Ill., USA).

\section{Evaluation of Antiviral Response}

VR after ADV therapy was defined as a serum HBV DNA reduction in the undetectable levels $(<60 \mathrm{IU} / \mathrm{ml})$. HBeAg loss and seroconversion (for $\mathrm{HBeAg}$-positive patients) and biochemical response as serum ALT levels decreased to the normal range (up to $40 \mathrm{IU} / \mathrm{l}$ ) at the end of follow-up were analyzed. VBT was defined as an increase in the level of HBV DNA of at least $1 \log _{10} \mathrm{IU} / \mathrm{ml}$ from the nadir, and was repeatedly examined at intervals of at least 1 month intervals during the ADV treatment. Virological relapse was defined as detection of HBV DNA after achieving VR, but $<1 \log _{10} \mathrm{IU} / \mathrm{mL}$ [26]. All patients experiencing a confirmed VBT underwent viral resistance mutational analysis, which was performed by PCR and a direct sequencing method.

\section{Statistical Analysis}

Data were expressed as the mean with standard deviation (SD) for discrete variables and as counts and percentages for qualitative variables. Continuous variables were compared with the Student $t$ test and categorical variables were assessed using the $\chi^{2}$ test, the Fisher exact test or the Mann-Whitney $U$ test. The cumulative probabilities of achieving VR and VBT were assessed using the Kaplan-Meier method and the log-rank test. A logistic regression model was used for univariate and multivariate analysis for searching independent predictors of VR or VBT. A $p$ value $<0.05$ for 
Table 1. Baseline characteristics of 106 patients with LAM-resistant $\mathrm{CH}-\mathrm{B}$ treated with LAM + ADV combination therapy

\begin{tabular}{lc}
\hline Clinical characteristics & LAM + ADV \\
\hline Age, years & $48.5 \pm 10.1$ \\
Male & $73(68.9 \%)$ \\
Body mass index, kg/m² & $24.5 \pm 2.9$ \\
Compensated liver cirrhosis & $32(30.2 \%)$ \\
HBeAg positivity & $79(74.5 \%)$ \\
HBV DNA, log IU/ml & $6.23 \pm 1.24$ \\
ALT, IU/l & $259.6 \pm 393.5$ \\
Albumin, g/dl & $4.2 \pm 0.4$ \\
Bilirubin, mg/dl & $1.2 \pm 1.7$ \\
Platelet count, $\times 10^{3} / \mathrm{mm}^{3}$ & $164.1 \pm 59.8$ \\
Duration of prior LAM therapy, months & $26.7 \pm 14.8$ \\
Duration of ADV therapy, months & $55.2 \pm 16.8$ \\
VR at last follow-up & $73(68.8 \%)$ \\
VBT at last follow-up & $8(7.5 \%)$ \\
Virological relapse after VR & $17(21.5 \%)$ \\
\hline
\end{tabular}

Values are $n(\%)$ or mean \pm SD.

2-sided tests was considered to be statistically significant. Data handling and analysis were performed by SPSS software for Windows, version 18 (SPSS Inc., Chicago, Ill., USA).

\section{Results}

\section{The Overall Antiviral Efficacy of ADV Rescue}

Therapy for LAM-Resistant $C H$ - $B$

The clinical features and antiviral efficacy of ADV rescue therapy for 106 patients are summarized in table 1 . The overall cumulative probabilities of VR at 1,2, 3 and 5 years of ADV treatment were 40.6, 55.7, 64.6 and $81.3 \%$, respectively (fig. 1a), while the cumulative probabilities of VBT at $1,2,3$ and 5 years were $0,2.9,8.8$ and $13.9 \%$, respectively (fig. 1b).

Clinical variables were analyzed to search for predictors of VR by means of a logistic regression model (table 2). Among the variables, baseline HBV-DNA levels $[<6 \log \mathrm{IU} / \mathrm{ml}$; odds ratio (OR) 2.85, $\mathrm{p}=0.017]$ and $\mathrm{HBeAg}$ positivity (OR $0.33, \mathrm{p}=0.033$ ) were significantly associated with VR on the univariate analysis. The multivariate analysis using a step-wise logistic regression model showed that the baseline HBV-DNA level was an independent predictor for the VR of ADV therapy (OR 2.49, $\mathrm{p}=0.041$ ).

ADV treatment was well tolerated. The overall median serum creatinine level was $1.00 \pm 0.1 \mathrm{mg} / \mathrm{dl}$ at the baseline, and $0.97 \pm 0.2 \mathrm{mg} / \mathrm{dl}$ at the last follow-up. Only $1 / 106$

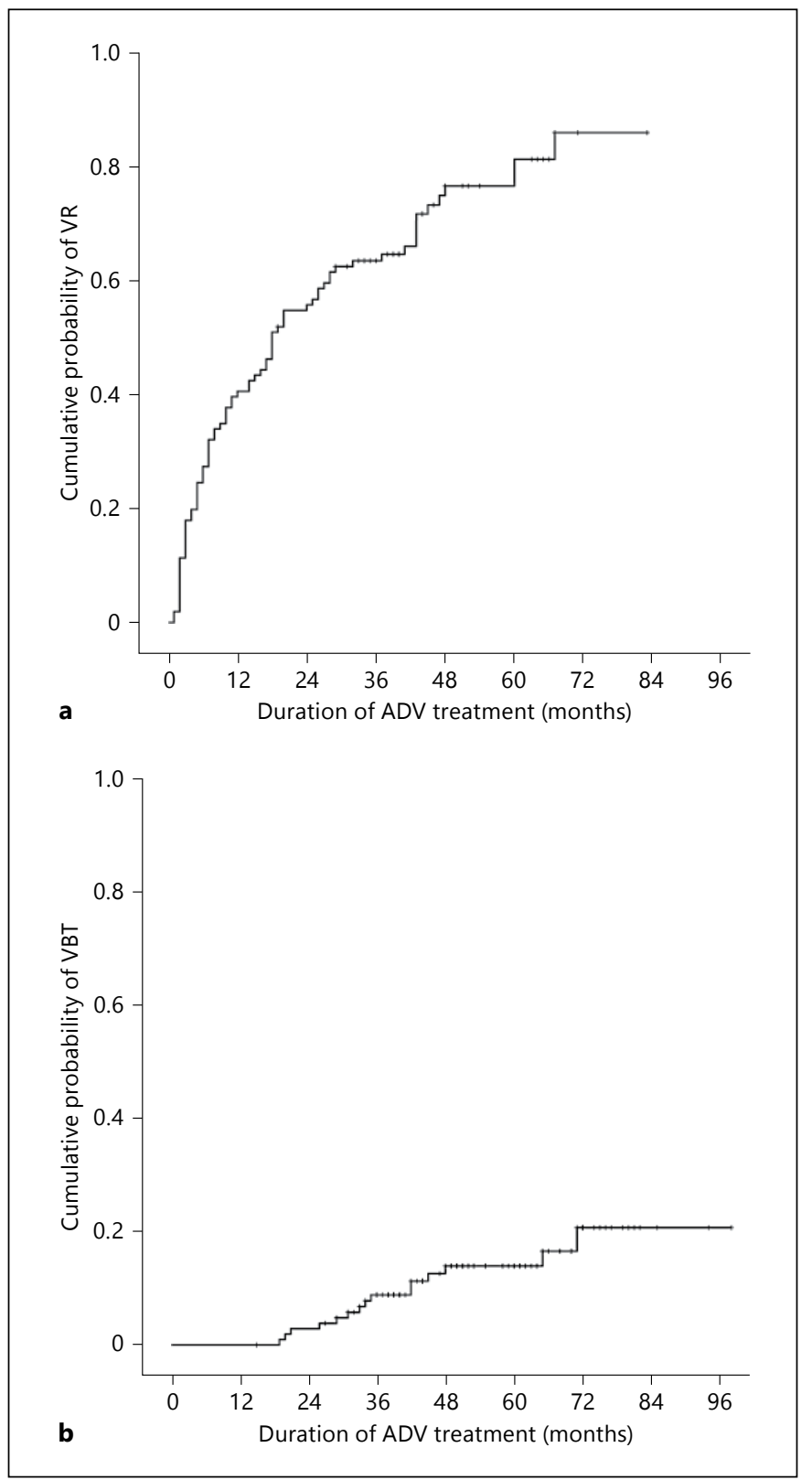

Fig. 1. The overall antiviral efficacy of LAM + ADV combination therapy in $106 \mathrm{LAM}$-resistant $\mathrm{CH}-\mathrm{B}$ patients. a Overall cumulative probability of the VR. b Overall cumulative probability of the VBT. VR was defined as an undetectable serum HBV DNA level $<60$ IU/ $\mathrm{ml}$ and VBT as an increase in serum HBV DNA level of at least $1 \log _{10} \mathrm{IU} / \mathrm{ml}$ from the nadir.

patients $(0.9 \%)$ had an increase in serum creatinine level of $>0.5 \mathrm{mg} / \mathrm{dl}$ during ADV therapy. An elevation in creatinine level from 1.1 to $2.2 \mathrm{mg} / \mathrm{dl}$ was observed in this patient after 37 months of ADV therapy; after dose reduction, their renal function improved. 
Table 2. Univariate and multivariate analysis of predictors associated with the VR of ADV rescue therapy in 106 LAM-resistant $\mathrm{CH}-\mathrm{B}$ patients

\begin{tabular}{|c|c|c|c|c|}
\hline \multirow[t]{2}{*}{ Variables } & \multicolumn{2}{|c|}{ Univariate analysis } & \multicolumn{2}{|c|}{ Multivariate analysis } \\
\hline & OR (95\% CI) & $\mathrm{p}$ value & OR $(95 \% \mathrm{CI})$ & $\mathrm{p}$ value \\
\hline Age (per year) & $1.01(0.98-1.05)$ & 0.517 & & \\
\hline Male gender & $0.48(0.21-1.10)$ & 0.084 & & \\
\hline Cirrhosis (yes vs. no) & $1.26(0.58-2.75)$ & 0.560 & & \\
\hline HBeAg positivity & $0.33(0.12-0.91)$ & $0.033^{\mathrm{a}}$ & $0.39(0.14-1.10)$ & 0.075 \\
\hline HBV DNA $(\log \mathrm{IU} / \mathrm{ml}<6)$ & $2.85(1.21-6.72)$ & $0.017^{\mathrm{a}}$ & $2.49(1.04-5.98)$ & $0.041^{\mathrm{a}}$ \\
\hline Albumin (per g/dl) & $1.10(0.45-2.74)$ & 0.831 & & \\
\hline Bilirubin (per mg/dl) & $0.99(0.82-1.18)$ & 0.869 & & \\
\hline Creatinine (per mg/dl) & $0.34(0.61-1.87)$ & 0.215 & & \\
\hline \multicolumn{5}{|l|}{ ALT } \\
\hline$<2$ times UNL & 1 & 0.840 & & \\
\hline 2-5 times UNL & $1.04(0.45-2.38)$ & 0.923 & & \\
\hline$\geq 5$ times UNL & $1.29(0.52-3.18)$ & 0.581 & & \\
\hline Prothrombin time (INR) & $1.05(0.82-1.33)$ & 0.709 & & \\
\hline Platelets $\left(\right.$ per $\left.10^{3} / \mu \mathrm{l}\right)$ & $1.00(0.99-1.01)$ & 0.313 & & \\
\hline \multicolumn{5}{|l|}{ ADV treatment } \\
\hline Switch therapy & 1 & & & \\
\hline Add-on therapy & $2.03(0.96-4.26)$ & 0.063 & & \\
\hline
\end{tabular}

\section{Feasibility of Discontinuing LAM after VR during}

$L A M+A D V$ Combination Therapy

Of the 74 patients who had achieved VR during LAM + ADV combination therapy, 39 discontinued LAM within 12 months of the VR (LAM-discontinuation group) and 35 continued LAM + ADV for $>12$ months after VR (LAM-continuation group). VR was confirmed by the negative HBV DNA levels on the repeated tests done at intervals of 1-4 months. Comparison of the baseline clinical characteristics and treatment outcomes between the 2 groups are summarized in table 3. There was no significant difference in the baseline characteristics and therapeutic outcomes, except in the duration of LAM treatment after VR. One patient from each group experienced VBT at the last follow-up, and maintenance of the VR until then was found in 35 patients $(89.7 \%)$ in the LAM-discontinuation group and in $33(94.3 \%)$ in the LAM-continuation group ( $\mathrm{p}=$ 0.677 ). The cumulative probabilities of virological relapse in the LAM-discontinuation group were not statistically different from those in the LAM-continuation group (log-rank test, $\mathrm{p}=0.442$; fig. 2 ). Two patients displaying VBT received ETV rescue therapy, either as ETV only or ETV + ADV combination therapy. Of 4 patients showing a virological relapse, 2 received TDF and the other 2 added LAM to ADV monotherapy.

\section{Discussion}

In this study, $\mathrm{ADV}$ rescue therapy for LAM-resistant $\mathrm{CH}-\mathrm{B}(\mathrm{n}=106$, mean therapy duration 55.2 months) resulted in a 5-year cumulative probability of VR and VBT of 81.3 and $13.9 \%$, respectively. At the last follow-up, ALT normalization was found in $82.1 \%$ of the patients. After achieving VR during LAM + ADV combination therapy $(n=74)$, whether LAM was continued or not, the VR and VBT did not change; this suggests that LAM discontinuation is feasible in these patients.

The rescue options for LAM-resistant $\mathrm{CH}$-B patients in Korea until 2012 were LAM + ADV combination, 'LAM to ADV switch' and 'LAM to $1 \mathrm{mg}$ of ETV switch' therapy [18-20]. The option of LAM + ADV combination therapy was superior to the 'LAM to ADV switch' or 'LAM to $1 \mathrm{mg}$ of ETV switch' therapy in previous reports [13-15, 17-19, 27]. However, since 2013, TDF has been 
Table 3. Comparison of clinical characteristics and VR, VBT and virological relapse rates between the LAM-continuation group and the LAM-discontinuation group after achieving a VR on LAM + ADV combination therapy

\begin{tabular}{lcc}
\hline Variables & $\begin{array}{l}\text { LAM-discontinuation } \\
\text { group }^{\mathrm{a}}(\mathrm{n}=39)\end{array}$ & $\begin{array}{l}\text { LAM-continuation } \\
\text { group }^{\mathrm{b}}(\mathrm{n}=35)\end{array}$ \\
\hline Age, years & $51.0 \pm 9.0$ & $46.7 \pm 10.5$ \\
Male/female & $22 / 17$ & $26 / 9$ \\
HBeAg positivity & $24(61.5)$ & $26(74.3)$ \\
Baseline HBV DNA, log IU/ml & $5.91 \pm 1.29$ & $6.13 \pm 1.30$ \\
ALT, IU/l & $261.9 \pm 286.1$ & $229.6 \pm 424.3$ \\
Creatinine, mg/dl & $0.95 \pm 0.29$ & $1.07 \pm 0.14$ \\
Duration of total ADV treatment, months & $55.4 \pm 17.1$ & $58.9 \pm 12.8$ \\
Duration of LAM treatment after VR, months & $4.9 \pm 3.1$ & $23.7 \pm 10.0$ \\
HBeAg loss at last follow-up & $14(35.9)$ & $14(40.0)$ \\
HBeAb seroconversion at last follow-up & $5(12.8)$ & $6(17.1)$ \\
HBV DNA, log IU/ml at last follow-up & $1.95 \pm 0.66$ & $1.91 \pm 0.54$ \\
Creatinine level, mg/dl at last follow-up & $0.95 \pm 0.24$ & $0.98 \pm 0.18$ \\
VR at last follow-up & $35(89.7)$ & $33(94.3)$ \\
Biochemical response at last follow-up & $35(89.7)$ & $28(80.0)$ \\
VBT at last follow-up & $1(2.6)$ & $1(2.9)$ \\
Virological relapse at last follow-up & $3(7.7)$ & $1(2.9)$ \\
\hline
\end{tabular}

Values denote $\mathrm{n}(\%)$ or a mean \pm SD.

${ }^{a}$ LAM was discontinued according to the LAM overlap period of 12 months after achieving a VR.

${ }^{b}$ LAM was continued according to the LAM overlap period of 12 months after achieving a VR.

${ }^{c}$ Virological relapse: HBV DNA detectable after achieving a VR.

d Analysis was performed by Mann-Whitney U test.

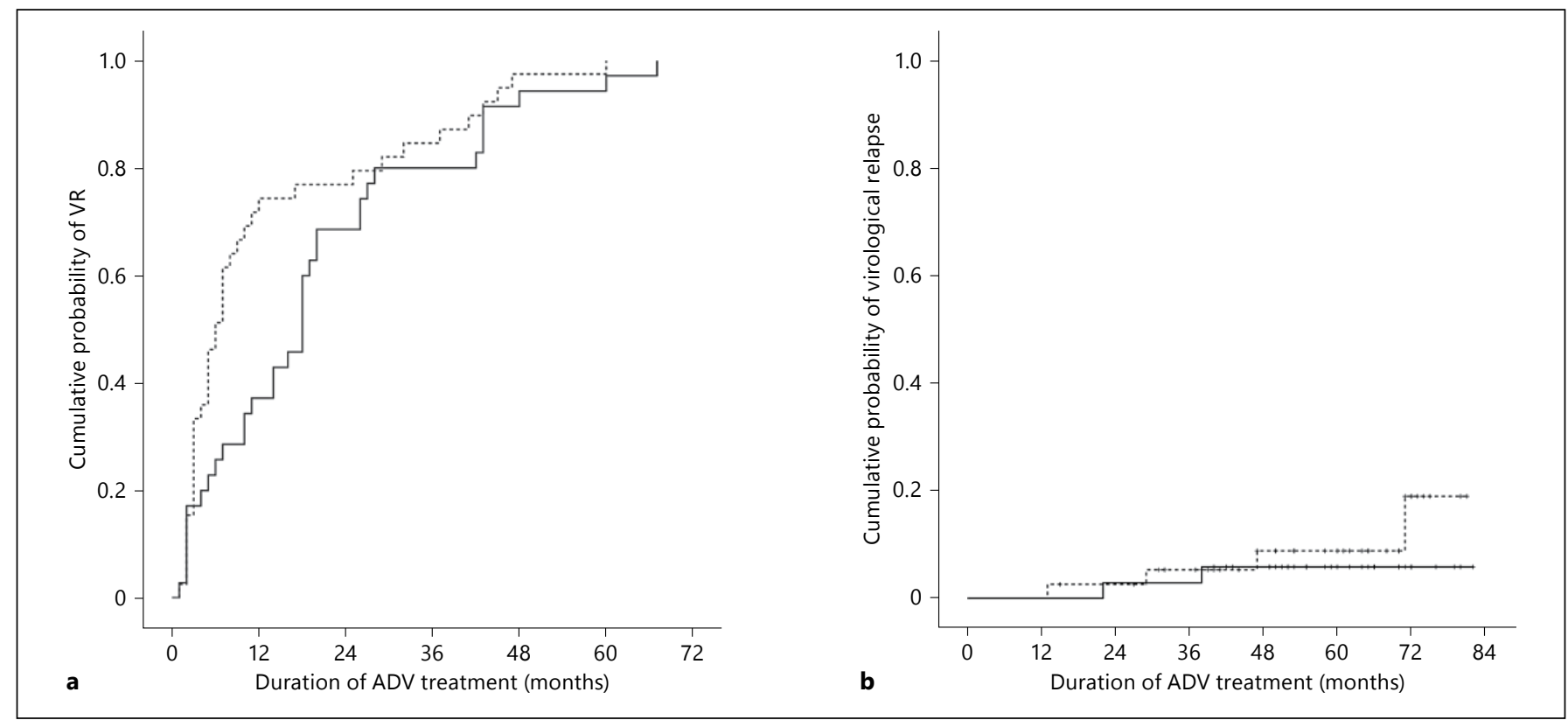

Fig. 2. The comparison of VR and virological relapse between the LAM-continuation group $(\mathrm{n}=39)$ and the LAM-discontinuation group $(\mathrm{n}=35)$ after achieving VR on LAM + ADV combination therapy. a Comparison of cumulative probabilities of VR showed no significant difference between the LAM-continuation group (solid line) and the LAM-discontinuation group (dotted line). $\mathrm{p}=$
0.065, log-rank test. $\mathbf{b}$ Comparison of cumulative probabilities of virological relapse showed no significant difference between the LAM-continuation group (solid line) and the LAM-discontinuation group (dotted line) after achieving VR on LAM + ADV combination therapy. $\mathrm{p}=0.442$, log-rank test. 
the best option for the rescue of LAM resistance, either as a TDF monotherapy or LAM + TDF in combination, with recent studies showing these to be comparable [28, 29].

Toyama et al. [30] reported that the overall VR at 4 years of ADV rescue therapy for LAM-resistant $\mathrm{CH}-\mathrm{B}$ was $90.8 \%$, and the rate of HBeAg loss at the end of follow-up was $34.0 \%$. In this study, ADV rescue therapy for LAM-resistant $\mathrm{CH}-\mathrm{B}$ showed cumulative probabilities of VR of $40.6,55.7,64.6$ and $81.3 \%$ at $1,2,3$ and 5 years, respectively, and of VBT of $0,2.9,8.8$ and $13.9 \%$ at $1,2,3$ and 5 years, respectively. In the $\mathrm{HBeAg}$-positive patients $(\mathrm{n}=79)$, the rate of HBeAg loss and of HBeAb seroconversion were 44.3 and $17.7 \%$, respectively.

In previous studies, the predictors for $\mathrm{VR}$ to $\mathrm{ADV}$ therapy in nucleos $(\mathrm{t})$ ide-naïve and LAM-resistant $\mathrm{CH}-\mathrm{B}$ patients have been reported to be female gender, negative HBeAg, lower baseline HBV DNA, higher ALT level and genotype $\mathrm{D}$ (rather than A) [5, 11-15, 27, 31, 32]. Our results were partially in agreement, with the viral load before ADV therapy being independent predictors for the VR, whereas HBeAg positivity and ALT level were not significant predictors, probably because $\mathrm{HBeAg}$ positivity is strongly correlated with viral load. Therefore, ADV therapy should be initiated as soon as possible after confirmation of resistance to LAM during LAM therapy before elevation of HBV DNA levels occurs. Renal impairment during ADV therapy was observed in only 1 of all of the 106 patients $(0.9 \%)$ in our study, suggesting that ADV rescue therapy has a good safety profile.

To find out the feasibility of discontinuing LAM in patients on LAM + ADV combination therapy once VR had been achieved, we compared the VR, VBT and virological relapse of the LAM-discontinuation group and the LAMcontinuation group. The results showed no significant between-group differences in the maintenance of these, so we concluded that LAM could be discontinued after VR was confirmed. This was in agreement with those of a recent study by Kim et al. [33], reporting a VR rate of 94.4\% to have been sustained once LAM had been discontinued in $\mathrm{CH}-\mathrm{B}$ patients with LAM + ADV combination therapy; however, the follow-up period of 2 years in their study was relatively short. The rationale for LAM discontinuation after VR was based on the supposition that ADV alone can control a very low titer of both LAM-resistant and wild-type HBV at the status of VR, and that the LAM discontinuation may reduce the LAM-resistant viral subpopulation, possibly further reducing the development of multidrug resistance. Moreover, medical costs and potential long-term adverse effects related to indefinite LAM combination therapy are reduced.

The limitations of our study were that it was retrospective and a single-center experience as well as the period of administration of the LAM combination therapy being so variable (a mean overlap period of 4.95 months) and the number of patients in the LAM-discontinuation group being small. Although the sample size of this study was small, enrollment of more patients was impossible because TDF became available in South Korea in January 2013. However, our subjects were a consecutively enrolled cohort without arbitrary selection, and most of the required data for this study were available in the medical records.

In conclusion, long-term ADV rescue therapy for LAM-resistant $\mathrm{CH}-\mathrm{B}$ showed a good antiviral response, and the independent predictor for the VR was a lower HBV DNA titer at baseline. LAM could be discontinued for LAM resistant patients who achieved VR during LAM + ADV combination therapy. Long-term follow up study is warranted to confirm our results.

\section{References}

$>1$ Fung SK, Wong F, Hussain M, Lok AS: Sustained response after a 2-year course of lamivudine treatment of hepatitis B e antigen-negative chronic hepatitis B. J Viral Hepat 2004; 11:432-438

-2 Lok AS, McMahon BJ: Chronic hepatitis B: Update of recommendations. Hepatology 2004;39:857-861.

$>3$ Degertekin B, Lok AS: Update on viral hepatitis: 2008. Curr Opin Gastroenterol 2009;25: 180-185.

$>4$ Lok AS, McMahon BJ: Chronic hepatitis B: update 2009. Hepatology 2009;50:661662.

5 Hadziyannis SJ, Tassopoulos NC, Heathcote EJ, Chang TT, Kitis G, Rizzetto M, Marcellin
P, Lim SG, Goodman Z, Ma J, Arterburn S, Xiong S, Currie G, Brosgart CL: Long-term therapy with adefovir dipivoxil for HBeAgnegative chronic hepatitis B. N Engl J Med 2005;352:2673-2681.

$\checkmark 6$ Hadziyannis SJ, Tassopoulos NC, Heathcote EJ, Chang TT, Kitis G, Rizzetto M, Marcellin P, Lim SG, Goodman Z, Ma J, Brosgart CL, Borroto-Esoda K, Arterburn S, Chuck SL: Long-term therapy with adefovir dipivoxil for HBeAg-negative chronic hepatitis B for up to 5 years. Gastroenterology 2006;131:17431751 .

-7 Dienstag JL, Goldin RD, Heathcote EJ, Hann HW, Woessner M, Stephenson SL, Gardner S, Gray DF, Schiff ER: Histological outcome during long-term lamivudine therapy. Gastroenterology 2003;124:105-117.

8 Lee YS, Suh DJ, Lim YS, Jung SW, Kim KM, Lee HC, Chung YH, Lee YS, Yoo W, Kim SO: Increased risk of adefovir resistance in patients with lamivudine-resistant chronic hepatitis B after 48 weeks of adefovir dipivoxil monotherapy. Hepatology 2006;43:1385-1391.

$>$ Leung NW, Lai CL, Chang TT, Guan R, Lee CM, Ng KY, Lim SG, Wu PC, Dent JC, Edmundson S, Condreay LD, Chien RN: Extended lamivudine treatment in patients with chronic hepatitis B enhances hepatitis B e antigen seroconversion rates: results after 3 years of therapy. Hepatology 2001;33: 1527-1532. 
10 Peters MG, Hann Hw H, Martin P, Heathcote EJ, Buggisch P, Rubin R, Bourliere M, Kowdley K, Trepo C, Gray Df D, Sullivan M, Kleber K, Ebrahimi R, Xiong S, Brosgart CL: Adefovir dipivoxil alone or in combination with lamivudine in patients with lamivudine-resistant chronic hepatitis B. Gastroenterology 2004;126:91-101.

11 Liu CJ, Kao JH, Chen PJ, Chen TC, Lin FY, Lai MY, Chen DS: Overlap lamivudine treatment in patients with chronic hepatitis B receiving adefovir for lamivudine-resistant viral mutants. J Viral Hepat 2006;13:387-395.

-12 Buti M, Elefsiniotis I, Jardi R, Vargas V, Rodriguez-Frias F, Schapper M, Bonovas S, Esteban R: Viral genotype and baseline load predict the response to adefovir treatment in lamivudine-resistant chronic hepatitis B patients. J Hepatol 2007;47:366-372.

$\checkmark 13$ Inoue J, Ueno Y, Wakui Y, Niitsuma H, Fukushima K, Yamagiwa Y, Shiina M, Kondo Y, Kakazu E, Tamai K, Obara N, Iwasaki T, Shimosegawa T: Four-year study of lamivudine and adefovir combination therapy in lamivudine-resistant hepatitis B patients: influence of hepatitis B virus genotype and resistance mutation pattern. J Viral Hepat 2011;18:206215.

-14 Chen CH, Wang JH, Lu SN, Hu TH, Hung $\mathrm{CH}$, Chang $\mathrm{MH}$, Changchien $\mathrm{CS}$, Lee CM: Characteristics of adefovir resistance in patients with or without lamivudine-resistant hepatitis B virus treated with adefovir: a 4-year experience. Liver Int 2011;31:206-214.

15 Chen EQ, Wang LC, Lei J, Xu L, Tang H: Meta-analysis: adefovir dipivoxil in combination with lamivudine in patients with lamivudineresistant hepatitis B virus. Virol J 2009;6:163.

16 Liaw YF, Lee CM, Chien RN, Yeh CT: Switching to adefovir monotherapy after emergence of lamivudine-resistant mutations in patients with liver cirrhosis. J Viral Hepat 2006;13: 250-255.

17 Rapti I, Dimou E, Mitsoula P, Hadziyannis SJ: Adding-on versus switching-to adefovir therapy in lamivudine-resistant $\mathrm{HBeAg-negative}$ chronic hepatitis B. Hepatology 2007;45:307313.

18 Cho SW, Cho YJ, Cheong JY, Lee MH, Jeon SJ, Lee YC, Lim SG, Kang CJ: Add on lamivudine to adefovir monotherapy for the treatment of lamivudine-resistant chronic hepatitis B patients. Korean J Gastroenterol 2010;56: 83-89.
19 Aizawa M, Tsubota A, Fujise K, Sato K, Baba M, Takamatsu M, Namiki Y, Ohkusa T, Tajiri H: Overlap/switch to adefovir monotherapy for lamivudine-resistant patients who responded to combination therapy: a pilot controlled study. Intern Med 2010;49:1067-1072.

20 Lee HC: Lamivudine and adefovir combination therapy in lamivudine-resistant $\mathrm{HBeAg}$ positive chronic hepatitis B patients. Korean J Med 2009;77:713-715.

21 Fung SK, Chae HB, Fontana RJ, Conjeevaram $\mathrm{H}$, Marrero J, Oberhelman K, Hussain M, Lok AS: Virologic response and resistance to adefovir in patients with chronic hepatitis B. J Hepatol 2006;44:283-290.

22 Marcellin P, Chang TT, Lim SG, Sievert W, Tong M, Arterburn S, Borroto-Esoda K, Frederick D, Rousseau F: Long-term efficacy and safety of adefovir dipivoxil for the treatment of hepatitis $B$ e antigen-positive chronic hepatitis B. Hepatology 2008;48:750-758.

23 Shin SR, Koh KC, Gwak GY, Choi MS, Lee JH, Paik SW, Yoo BC: A low viral load predicts a higher initial virologic response to adefovir in patients with lamivudine-resistant chronic hepatitis B. Gut Liver 2010;4:530-536.

24 Aizawa M, Tsubota A, Fujise K, Tatsuzawa K, Kono M, Hoshina S, Tajiri H: Clinical course and predictive factors of virological response in long-term lamivudine plus adefovir dipivoxil combination therapy for lamivudine-resistant chronic hepatitis B patients. J Med Virol 2011;83:953-961.

25 Jung YK, Yeon JE, Han WS, Kim JH, Kim JH, Park JJ, Kim JS, Bak YT, Yoo W, Hong SP, Kim SO, Kwon SY, Byun KS, Lee CH: Virologic response at 12 months of treatment predicts sustained antiviral efficacy in patients with adefovir-treated lamivudine-resistant chronic hepatitis B. Gut Liver 2010;4:212218.

26 Liang Y, Jiang J, Su M, Liu Z, Guo W, Huang $\mathrm{X}$, Xie R, Ge S, Hu J, Jiang Z, Zhu M, Wong VW, Chan HL: Predictors of relapse in chronic hepatitis B after discontinuation of anti-viral therapy. Aliment Pharmacol Ther 2011; 34:344-352.
27 Chung GE, Kim W, Lee KL, Hwang SY, Lee JH, Kim HY, Jung YJ, Kim D, Jeong JB, Kim BG, Kim YJ, Yoon JH, Lee HS: Add-on adefovir is superior to a switch to entecavir as rescue therapy for lamivudine-resistant chronic hepatitis B. Dig Dis Sci 2011;56:2130-2136.

28 van Bommel F, de Man RA, Wedemeyer H, Deterding K, Petersen J, Buggisch P, Erhardt A, Huppe D, Stein K, Trojan J, Sarrazin C, Bocher WO, Spengler U, Wasmuth HE, Reinders JG, Moller B, Rhode P, Feucht HH, Wiedenmann $B$, Berg T: Long-term efficacy of tenofovir monotherapy for hepatitis B virus-monoinfected patients after failure of nucleoside/nucleotide analogues. Hepatology 2010;51:73-80.

29 Glyn F, Gill US, Alazawi W, Ross V, Kooner P, Marley R, Foster GR, Kennedy PTF: Efficacy of combination tenofovir plus lamivudine versus tenofovir monotherapy in patients with chronic hepatitis B virus (abstract). Gut 2011;60:A231.

30 Toyama T, Ishida H, Ishibashi H, Yatsuhashi H, Nakamuta M, Shimada M, Ohta H, Satoh T, Kato M, Hijioka T, Takano H, Komeda T, Yagura M, Mano H, Watanabe Y, Kobayashi M, Mita E: Long-term outcomes of add-on adefovir dipivoxil therapy to ongoing lamivudine in patients with lamivudine-resistant chronic hepatitis B. Hepatol Res 2012;42: 1168-1174.

31 Mitsui F, Tsuge M, Kimura T, Kitamura S, Abe $\mathrm{H}$, Saneto $\mathrm{H}$, Kawaoka T, Miki D, Hatakeyama $T$, Hiraga $N$, Imamura $M$, Kawakami Y, Aikata H, Takahashi S, Hayes $\mathrm{CN}$, Igarashi $\mathrm{H}$, Morimoto $\mathrm{K}$, Shimizu $\mathrm{M}$, Chayama K: Importance of serum concentration of adefovir for lamivudine-adefovir combination therapy in patients with lamivudineresistant chronic hepatitis B. Antimicrob Agents Chemother 2010;54:3205-3211.

-32 Shakado S, Watanabe H, Tanaka T, Morihara D, Nishizawa S, Inomata S, Ueda S, Matsumoto T, Anan A, Takeyama Y, Irie M, Iwata K, Sohda T, Sakisaka S: Combination therapy of lamivudine and adefovir in Japanese patients with chronic hepatitis B. Hepatol Int 2008;2:361-369.

- 33 Kim MN, Lee CK, Ahn SH, Lee S, Kim SU, Kim DY, Kim HS, Han KH, Chon CY, Park JY: Maintaining remission in lamivudine-resistant patients with a virological response to adefovir add-on lamivudine after stopping lamivudine therapy. Liver Int 2013. DOI: 10.1111/liv.12437. 